\title{
Retrospective analysis of the correlation between tacrolimus concentrations measured in whole blood and variations of blood cell counts in patients undergoing allogeneic haematopoietic stem cell transplantation
}

\author{
Naoki Yoshikawa, Shuhei Urata, Kazuya Yasuda, Hiroshi Sekiya, Yasutoshi Hirabara, \\ Manabu Okumura, Ryuji Ikeda
}

\begin{abstract}
- Additional material is published online only. To view please visit the journal online (http://dx.doi.org/ 10.1136/ejhpharm-2018001663).
\end{abstract}

Department of Pharmacy, University of Miyazaki Hospital, Miyazaki, Japan

Correspondence to Dr Naoki Yoshikawa, Department of Pharmacy, University of Miyazaki Hospital, Miyazaki 889-1692,Japan; naoki_yoshikawa@med. miyazaki-u.ac.jp

Received 2 July 2018 Revised 16 October 2018 Accepted 23 October 2018 Published Online First 16 November 2018

EAHP Statement 6: Education and Research.

\begin{abstract}
Objective Tacrolimus is administered to patients undergoing haematopoietic stem cell transplantation (HSCT) as prophylaxis for graft-versus-host disease. As a high blood tacrolimus concentration within a narrow therapeutic range must be maintained after HSCT, therapeutic drug monitoring (TDM) is necessary. We investigated the correlation between blood tacrolimus concentration and blood cell count in HSCT patients to assess how changes in blood cell count affect tacrolimus TDM.

Methods A retrospective analysis was performed for 24 patients who underwent allogeneic HSCT and received tacrolimus. The correlation between variations in blood tacrolimus concentration and blood cell count was evaluated for three consecutive weeks, starting 1 week after HSCT.
\end{abstract}

Results Variations in blood tacrolimus concentration were significantly correlated with variations in red blood cell (RBC) count, haemoglobin level and haematocrit value, but not with variations in white blood cell or platelet counts. Further, the above variations were significantly correlated in patients undergoing cord blood transplantation and peripheral blood stem cell transplantation, but not in those undergoing bone marrow transplantation.

Conclusions These findings demonstrate that RBC count is associated with variations in blood tacrolimus concentration, with the relevance of this association depending on the source of transfused stem cells. Thus, variations in RBC count might be useful for tacrolimus TDM.

\section{INTRODUCTION}

Haematopoietic stem cell transplantation (HSCT) is used to cure haemodyscrasias such as haematological cancers. Although HSCT is effective, some patients experience graft-versus-host disease (GVHD) after treatment, and this remains a major cause of non-relapse mortality in HSCT patients. Calcineurin inhibitors such as tacrolimus and ciclosporin are used for GVHD prophylaxis. It has been reported that the incidence of acute GVHD is lower with tacrolimus than with ciclosporin treatment, although the overall survival rate using either drug is similar. ${ }^{1-3}$ Furthermore, a correlation between

\section{What this paper adds}

What is already known on this subject

- Tacrolimus is mainly present in circulating red blood cells (RBCs).

- Little is known about the correlation between blood tacrolimus concentration and RBC count.

What this study adds

- Tacrolimus blood concentration is affected by short-term variations in RBC count.

- Control of blood tacrolimus concentration in cord blood transplantation and peripheral blood stem cell transplantation patients might be possible by monitoring variations in blood cell count.

blood tacrolimus concentration and its clinical efficacy and toxicity has been reported. ${ }^{4}$ However, the therapeutic range of tacrolimus concentration in blood is narrow, ${ }^{45}$ and there is a high variation of tacrolimus distribution in the body between individuals. Therefore, therapeutic drug monitoring (TDM) is important during GVHD prophylaxis with tacrolimus in HSCT patients.

Tacrolimus is mainly present in circulating red blood cells (RBCs), and its binding capacity is around $440 \mathrm{ng} / \mathrm{mL}$ RBCs. ${ }^{67}$ Although the plasma concentration of tacrolimus is important for its immunosuppressive effect, TDM is generally performed using whole blood, as this is easier to measure. Therefore, a variation in RBC count may affect tacrolimus concentration in whole blood. Results of clinical and in vitro studies conducted so far suggest that haematocrit $(\mathrm{Ht})$ is an important factor affecting tacrolimus pharmacokinetics. ${ }^{7-11}$ However, little is known about the correlation between blood tacrolimus concentration and RBC count.

After HSCT, blood tacrolimus concentration must be maintained at a high level and within a narrow range; therefore, proper control and adequate prediction of tacrolimus concentration in blood are required. In addition, there is usually a marked variation in blood cell count after HSCT. Thus, understanding the correlation between blood tacrolimus concentration and RBC count is 
important for the successful TDM of tacrolimus. In the present study, we retrospectively investigated the correlation between tacrolimus concentrations measured in whole blood and variations of blood cell counts in HSCT patients. This study was conducted to evaluate the effect of monitoring variations in $\mathrm{RBC}$ count on the TDM of tacrolimus.

\section{METHODS}

Patients

Only inpatients who underwent HSCT and received tacrolimus for GVHD prophylaxis at the Department of Hematology, University of Miyazaki Hospital (Miyazaki, Japan), from April 2015 to March 2017, were eligible for this study.

\section{Administration of tacrolimus and monitoring of its concentration in blood}

Tacrolimus was initially administered at $0.03 \mathrm{mg} / \mathrm{kg} /$ day via a continuous intravenous infusion to all patients. The target blood concentration of tacrolimus was $12-15 \mathrm{ng} / \mathrm{mL}$. The concentration of tacrolimus in the blood was measured via a chemiluminescence immunoassay (ARCHITECT system; Abbott, Tokyo, Japan) and controlled by TDM and dose adjustment. The accuracy for measuring tacrolimus blood concentration was managed by measuring the quality control reagent and the coefficient of variation for 1 month and was maintained at less than 5\%.

\section{Collection of patient data}

Patient data were retrieved from the electronic health record system. The RBC count was monitored for three consecutive weeks, starting 1 week after HSCT. During this period, tacrolimus was continuously administered via an intravenous infusion. Analysis points, which were adopted for comparing variations in blood tacrolimus concentration and blood cell count, were set as the points at which the RBC count varied by $10 \%$ or more from that of the previous examination. Variations in blood tacrolimus concentration were calculated at the same points. Additionally, the correlation between variations in blood tacrolimus concentration (\%) and blood cell count (\%) was evaluated. We excluded analysis points from the day after adjusting the dose of tacrolimus, as well as those within 3 days after adding or withdrawing any drug known to interact with tacrolimus. A correlation analysis was performed for patient groups that had been stratified by characteristics and source of transfused stem cells. For age and body weight, patients were divided into two groups based on the average value of all patients. If multiple analysis points were obtained for the same patient, all points were used in the correlation analysis. Creatinine clearance (CLcre) was calculated using the Cockcroft-Gault formula. The hepatic function and renal function of the target patient did not fluctuate remarkably during the evaluation period.

\section{Statistical analysis}

Analyses were performed for patient groups that had been stratified by body weight, age, gender and source of transfused stem cells. The correlation between variation in blood tacrolimus concentration and variation of blood cell counts was evaluated using Pearson's product-moment correlation coefficient. Statistical comparisons of patient characteristics were performed using Tukey's test for multiple comparisons. Gender bias among patients who were classified according to the source of transfused stem cells was evaluated using Fisher's exact test. All tests were conducted using R V.3.3.3 (www.r-project.org), with a significance level of $5 \%$.
Table 1 Patient characteristics

\begin{tabular}{|c|c|c|c|}
\hline $\begin{array}{l}\text { Patients ( } \mathrm{n} \text { ) (male/ } \\
\text { female) }\end{array}$ & & 24 & $(13 / 11)$ \\
\hline \multirow{3}{*}{$\begin{array}{l}\text { Classification of } \\
\text { transplantation (male/ } \\
\text { female) }\end{array}$} & BMT & 7 & $(4 / 3)$ \\
\hline & CBT & 12 & $(6 / 6)$ \\
\hline & PBSCT & 5 & $(3 / 2)$ \\
\hline Age (years) & & 56.2 & $(36-69)$ \\
\hline Body weight (kg) & & 56.2 & (32.9-84.1) \\
\hline RBC count $\left(10^{9} / \mathrm{L}\right)$ & & 2440 & $(1810-3460)$ \\
\hline Ht value (\%) & & 22.8 & $(16.3-34.1)$ \\
\hline Analysis points & & & 54 \\
\hline \multicolumn{4}{|c|}{$\begin{array}{l}\text { Age and body weight are expressed as average values with the range in brackets. } \\
\text { RBC count and } \mathrm{Ht} \text { value are expressed as average values at transplantation date, } \\
\text { with the range in brackets. } \\
\text { BMT, bone marrow transplantation; CBT, cord blood transplantation; } \mathrm{Ht} \text {, }\end{array}$} \\
\hline
\end{tabular}

\section{RESULTS}

\section{Patient characteristics}

Thirty-one patients underwent HSCT and were administered tacrolimus for GVHD prophylaxis from April 2015 to March 2017. Seven were excluded due to data insufficiency; therefore, 24 patients (13 male and 11 female) were included in the present analysis. The basic concomitant drugs during the period of tacrolimus administration were micafungin, levofloxacin, acyclovir, rabeprazole and ursodeoxycholic acid. Depending on the patient, rabeprazole was changed to $\mathrm{H}_{2}$ blocker or other proton pump inhibitor, and micafungin was changed to an azole antifungal agent. There were cases where mycophenolic acid was used in combination. Patient characteristics are shown in table 1. Allogeneic HSCT was classified according to the source of transfused stem cells, which included bone marrow (BMT, bone marrow transplantation), cord blood (CBT, cord blood transplantation) and peripheral blood stem cells (PBSCT, peripheral blood stem cell transplantation). Seven, 12 and 5 patients had undergone BMT, CBT and PBSCT, respectively. The RBC count and $\mathrm{Ht}$ value at transplantation date differed depending on the patient. The total number of analysis points was 54 .

\section{Trend of blood tacrolimus concentration during the survey period for HSCT patients}

The target range of blood tacrolimus concentration is $12-15 \mathrm{ng} /$ $\mathrm{mL}$; however, there could be some deviation during the survey period for HSCT patients (online supplementary figure 1). The target range achievement rate of blood tacrolimus concentration at the analysis point, with focus on the deviation at the analysis point, is shown in table 2. The percentage of controlling blood concentration of tacrolimus within the target range before

Table 2 Percentage of controlling blood tacrolimus concentration within the target range at analysis points

\begin{tabular}{lll} 
& \multicolumn{2}{l}{ Blood tacrolimus concentration } \\
\cline { 2 - 3 } & $\begin{array}{l}\text { Before RBC } \\
\text { variation }\end{array}$ & After RBC variation \\
\hline $\begin{array}{l}\text { Percentage of controlling blood } \\
\text { tacrolimus concentration within } \\
\text { the target range }\end{array}$ & $83.3(45 / 54)$ & $40.7(22 / 54)$ \\
\hline RBC, red blood cell. & & \\
\hline
\end{tabular}


Table 3 Correlation between the variations in blood tacrolimus concentration and blood cell count

\begin{tabular}{|c|c|c|c|c|c|}
\hline & RBC & $\mathrm{Hb}$ & $\mathrm{Ht}$ & WBC & Plt \\
\hline All patients $(n=54)$ & $0.616(<0.001)$ & $0.624(<0.001)$ & $0.630(<0.001)$ & $-0.060(0.667)$ & $0.038(0.785)$ \\
\hline BMT $(n=14)$ & $0.516(0.059)$ & $0.485(0.079)$ & $0.506(0.065)$ & $-0.084(0.777)$ & $0.143(0.625)$ \\
\hline CBT $(n=28)$ & $0.544(0.003)$ & $0.565(0.002)$ & $0.563(0.002)$ & $0.191(0.329)$ & $-0.056(0.776)$ \\
\hline PBSCT $(n=12)$ & $0.861(<0.001)$ & $0.874(<0.001)$ & $0.868(<0.001)$ & $-0.354(0.259)$ & $0.165(0.608)$ \\
\hline$B W \geq 56.2 \mathrm{~kg}(\mathrm{n}=21)$ & $0.665(<0.001)$ & $0.687(<0.001)$ & $0.663(0.001)$ & $-0.058(0.802)$ & $-0.017(0.953)$ \\
\hline BW $<56.2 \mathrm{~kg}(\mathrm{n}=33)$ & $0.591(<0.001)$ & $0.590(<0.001)$ & $0.611(<0.001)$ & $-0.076(0.673)$ & $0.062(0.731)$ \\
\hline Age $\geq 56.2$ years $(n=27)$ & $0.491(0.009)$ & $0.524(0.005)$ & $0.511(0.006)$ & $0.039(0.845)$ & $-0.054(0.789)$ \\
\hline Age $<56.2$ years $(n=27)$ & $0.711(<0.001)$ & $0.703(<0.001)$ & $0.722(<0.001)$ & $-0.106(0.600)$ & $0.219(0.271)$ \\
\hline Male $(n=31)$ & $0.521(0.003)$ & $0.546(0.002)$ & $0.538(0.002)$ & $0.087(0.641)$ & $-0.094(0.616)$ \\
\hline Female $(n=23)$ & $0.701(<0.001)$ & $0.696(<0.001)$ & $0.710(<0.001)$ & $-0.088(0.689)$ & $0.126(0.568)$ \\
\hline
\end{tabular}

Data are expressed as Pearson's correlation coefficients, and the $p$ value of each test is presented in brackets. ' $n$ ' represents the number of analysis points.

BMT, bone marrow transplantation; BW, body weight; CBT, cord blood transplantation; Hb, haemoglobin; Ht, haematocrit; PBSCT, peripheral blood stem cell transplantation; Plt, platelet; RBC, red blood cell; WBC, white blood cell.

variation in $\mathrm{RBC}$ count was higher than that after variation in $\mathrm{RBC}$ count.

\section{Correlation between variations in blood tacrolimus concentration and blood cell count}

Table 3 shows the results of the correlation analysis between variations in blood tacrolimus concentration and blood cell count in the various patient groups, stratified according to patient characteristics and source of transfused stem cells. Variations in tacrolimus concentration in whole blood were significantly correlated $(\mathrm{p}<0.05)$ with variations in RBC count, haemoglobin $(\mathrm{Hb})$ level and $\mathrm{Ht}$ value, but not with variations in white blood cell(WBC) count or platelet count. Figure 1 shows the scatter plot of variation in blood tacrolimus concentration versus variation in $\mathrm{RBC}$ count, $\mathrm{Hb}$ level or $\mathrm{Ht}$ value in all patients. A significant correlation $(\mathrm{p}<0.05)$ between variations in blood tacrolimus concentration and RBC count, Hb level and $\mathrm{Ht}$ value was only found for CBT and PBSCT patients.

In each body weight, age and gender group, a significant correlation $(\mathrm{p}<0.05)$ was found between variations in blood tacrolimus concentration and RBC count, $\mathrm{Hb}$ level and $\mathrm{Ht}$ value. The ratio of male to female, average ages, mean body weights, average alanine transaminase (ALT), average aspartate transaminase (AST), average total bilirubin (TB) and average CLcre in the BMT, CBT and PBSCT groups are shown in table 4 . No significant differences ( $p>0.05$ ) were noted in age, body weight, ALT, AST, TB or CLcre among HSCT patients, based on the classification according to the source of transfused stem cells.

\section{DISCUSSION}

The concentration of tacrolimus in blood is affected by several variables, including variations in RBC count, as shown in the present study. Tacrolimus is a macrolide immunosuppressant that is more potent than ciclosporin. ${ }^{12} 13$ Its immunosuppressive effect occurs via calcineurin inhibition through the formation of tacrolimus-FK506 binding protein (FKBP) complexes in $\mathrm{T}$ cells, followed by inhibition of cytokine production. ${ }^{14}$ Although FKBP12 and FKBP13 are very similar proteins, with molecular weights of 12 and $13 \mathrm{kDa}$, respectively, ${ }^{15} \mathrm{FKBP} 12$ is mainly associated with the immunosuppressive effect of tacrolimus and is localised in the cytosol of T cells, while FKBP13 is localised in the endoplasmic reticulum. ${ }^{16}$ In RBCs, FKBP12 and FKBP13 are localised in the cytosol and membrane, respectively. ${ }^{17}$ Therefore, tacrolimus is mainly present in circulating RBCs. A variation in RBC count is expected to affect blood tacrolimus concentration because more than $90 \%$ of the tacrolimus in circulation is confined to RBCs. ${ }^{7}{ }^{18}$ It has been reported that $\mathrm{Ht}$ affects the pharmacokinetics of tacrolimus by significantly altering blood tacrolimus concentration in liver transplant recipients. ${ }^{89}$ Furthermore, Zheng et $a l^{19}$ reported that oral clearance of tacrolimus is inversely correlated with RBC count. However, these reports only evaluate the relationship between $\mathrm{Ht}$ or RBC count at one point in time and the blood tacrolimus concentration. We demonstrate the novel finding that tacrolimus blood concentration is affected by short-term variations in RBC count or $\mathrm{Ht}$ value. In the present study, variations in $\mathrm{Ht}$ value were significantly and positively correlated with variations in the blood tacrolimus concentration. Additionally, variations in $\mathrm{RBC}$ count and $\mathrm{Hb}$ value were significantly correlated with variations in blood tacrolimus concentration, whereas no such correlation was noted with variations in WBC count or platelet counts. These results show that RBCs are associated with variations in blood tacrolimus concentration. Spallanzani et $a l^{20}$ reported success in decreasing blood tacrolimus concentration by performing $\mathrm{RBC}$ exchange in renal transplant patients overexposed to tacrolimus. Our findings support this result. Furthermore, in the present study, the analysis point was set based on the variation in RBC count. In addition, points considered to be affected by dose adjustment and addition or withdrawal of drugs known to interact with tacrolimus were excluded. We showed high achievement rate of controlling blood tacrolimus concentration within the target range before variation in RBC count (table 2). The blood tacrolimus concentration before variation in RBC count at analysis points is a point where the necessity of dose adjustment is low. Therefore, these data suggest that the variation in $\mathrm{RBC}$ count is a factor affecting appropriately controlled blood tacrolimus concentration.

In the patient-stratified analyses performed in this study, no correlation was observed between variations in blood tacrolimus concentration and $\mathrm{RBC}$ count, $\mathrm{Hb}$ level and $\mathrm{Ht}$ value in BMT patients. Furthermore, the likelihood of age, gender, hepatic function or renal function being related to this result was low. Other studies have also shown the effects of different stem cell sources. A meta-analysis by Holtick et $a l^{21}$ demonstrated that the time for engrafting neutrophils and platelets was significantly shorter in PBSCT than in BMT. Furthermore, Uchino et $a l^{22}$ reported that the proportion of patients with severe dry eyes after undergoing allogeneic HSCT was significantly higher after PBSCT than after BMT or CBT. Thus, the source of transfused stem cells greatly affects the patient's condition and seems to affect the pharmacokinetics of the administered drug. To our knowledge, the effects of stem cell source 


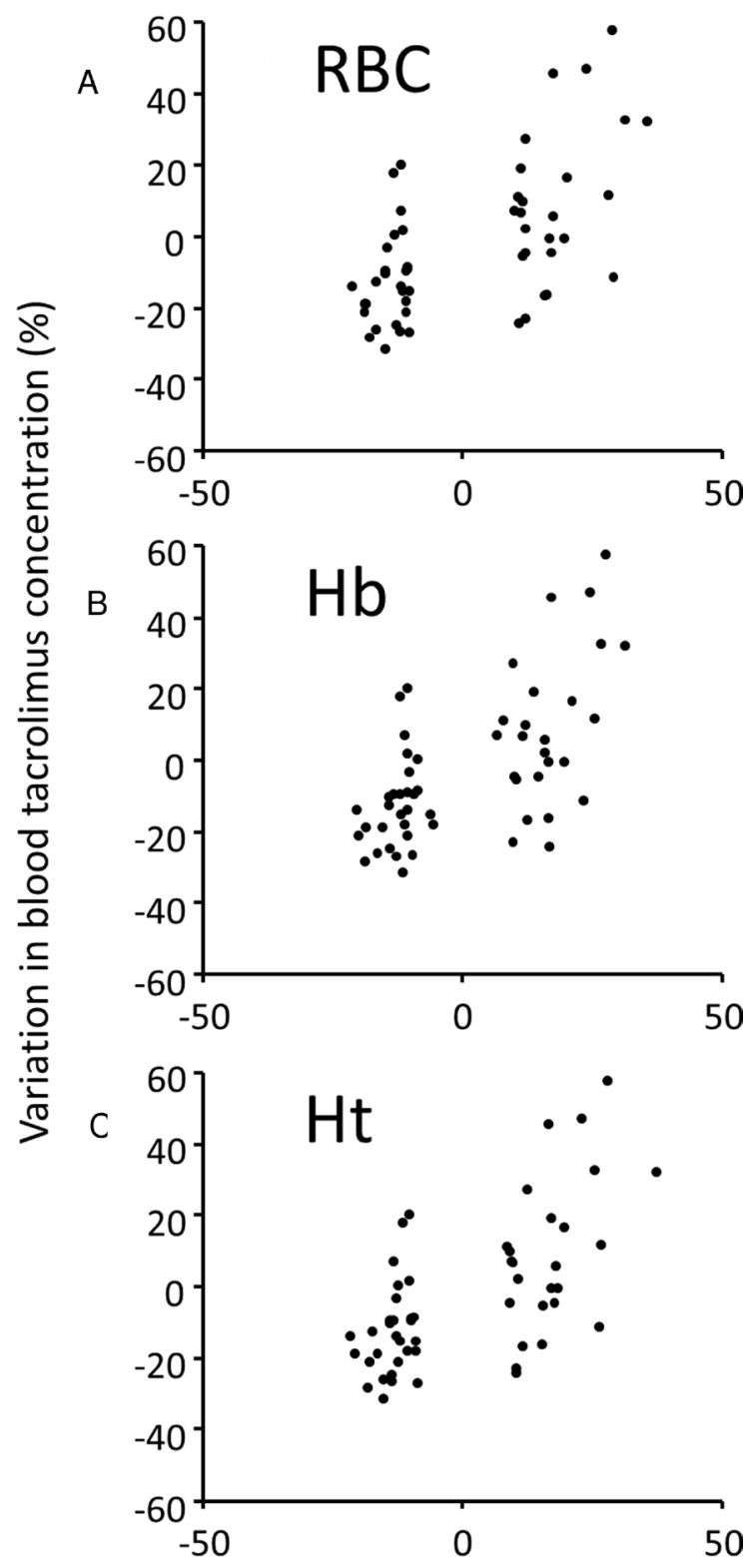

\section{Variation in blood cell count (\%)}

Figure 1 Scatter plot of variation in blood tacrolimus concentration versus variation in $\mathrm{RBC}$ count (A), Hb level (B) or Ht value (C) in all patients. The vertical axis and the horizontal axis indicate the variation in the blood cell count and the variation in the blood tacrolimus concentration in percentage, respectively. $\mathrm{Hb}$, haemoglobin; $\mathrm{Ht}$, haematocrit; $\mathrm{RBC}$, red blood cell.

on the pharmacokinetics of immunosuppressants have not been reported previously; therefore, the findings of the present study are valuable for understanding how these drugs are distributed within a patient's body.

There are certain limitations to this study. First, as this is a single-centre study, the target sample size was small and there was some bias in the source of transfused stem cell. Second, as this is a retrospective study, data obtained are limited. To guarantee the authenticity of the results obtained in this study, we think that it is necessary to verify the correlation between tacrolimus blood concentrations and variations of blood cell counts prospectively again.
Table 4 Comparison of patient baseline characteristics

\begin{tabular}{lclc}
\hline & BMT & CBT & PBSCT \\
\hline $\begin{array}{l}\text { Patients (n) (male/ } \\
\text { female) }\end{array}$ & $7(4 / 3)$ & $12(6 / 6)$ & $5(3 / 2)$ \\
\hline Age (years) & $50.4(36-63)$ & $60.5(44-69)$ & $54.0(47-67)$ \\
Body weight (kg) & $64.0(45.7-84.1)$ & $50.7(32.9-68.8)$ & $58.4(44.6-77.8)$ \\
ALT (U/L) & $26.7(15-44)$ & $40.2(15-77)$ & $43.0(11-110)$ \\
AST (U/L) & $27.7(14-55)$ & $44.5(19-116)$ & $40.6(9-127)$ \\
TB (mg/dL) & $0.96(0.4-2.7)$ & $0.95(0.5-2.0)$ & $0.80(0.2-2.2)$ \\
CLcre (mL/min) & $134.1(74.8-220.9)$ & $96.0(37.0-143.8)$ & $102.0(60.7-131.2)$ \\
Analysis point & 14 & 28 & 12 \\
\hline
\end{tabular}

Age, body weight, ALT, AST, TB and CLcre are expressed as average values at transplantation date with the range in brackets. There are no significant differences.

ALT, alanine transaminase; AST, aspartate transaminase; BMT, bone marrow

transplantation; $\mathrm{CBT}$, cord blood transplantation; $\mathrm{CL}$ cre, creatinine clearance; $\mathrm{PBSCT}$ peripheral blood stem cell transplantation; TB, total bilirubin

In the present study, we clarified the correlation between variations in blood tacrolimus concentration and variations in RBC count in HSCT patients. We found that variations in blood cell count in HSCT patients were particularly remarkable in the early stages after transplantation, corresponding to the period when blood tacrolimus concentration must be strictly controlled. This study showed that the source of transfused stem cell is one of the indicators of the amount of tacrolimus that is distributed into RBCs. There is no clear evidence on other indicators of the amount of tacrolimus that is distributed into RBCs. Based on the results of this study, control of blood tacrolimus concentration in CBT and PBSCT patients might be possible by monitoring the variations in blood cell count.

Acknowledgements We would like to thank Editage (www.editage.jp) for English language editing.

Contributors NY designed the study and wrote the initial draft of the manuscript. SU contributed to analysis and interpretation of data.

Funding The authors have not declared a specific grant for this research from any funding agency in the public, commercial or not-for-profit sectors.

Competing interests None declared.

Patient consent Not required.

Ethics approval This study was approved by the ethical review committee of the Faculty of Medicine at the University of Miyazaki, Japan (no 0-0197).

Provenance and peer review Not commissioned; externally peer reviewed.

\section{REFERENCES}

1 Ratanatharathorn V, Nash RA, Przepiorka D, et al. Phase III study comparing methotrexate and tacrolimus (prograf, FK506) with methotrexate and cyclosporine for graft-versus-host disease prophylaxis after HLA-identical sibling bone marrow transplantation. Blood 1998;92:2303-14.

2 Nash RA, Antin JH, Karanes C, et al. Phase 3 study comparing methotrexate and tacrolimus with methotrexate and cyclosporine for prophylaxis of acute graftversus-host disease after marrow transplantation from unrelated donors. Blood 2000;96:2062-8

3 Hiraoka A, Ohashi Y, Okamoto S, et al. Phase III study comparing tacrolimus (FK506) with cyclosporine for graft-versus-host disease prophylaxis after allogeneic bone marrow transplantation. Bone Marrow Transplant 2001;28:181-5.

4 Przepiorka D, Nash RA, Wingard JR, et al. Relationship of tacrolimus whole blood levels to efficacy and safety outcomes after unrelated donor marrow transplantation. Biol Blood Marrow Transplant 1999;5:94-7.

5 Mori T, Kato J, Shimizu T, et al. Effect of early posttransplantation tacrolimus concentration on the development of acute graft-versus-host disease after allogeneic hematopoietic stem cell transplantation from unrelated donors. Biol Blood Marrow Transplant 2012;18:229-34

6 Piekoszewski W, Chow FS, Jusko WJ, et al. FK 506) in rabbits. Role of red blood cell binding in hepatic clearance. Drug Metab Dispos 1993;21:690-8.

7 Chow FS, Piekoszewski W, Jusko WJ. Effect of hematocrit and albumin concentration on hepatic clearance of tacrolimus (FK506) during rabbit liver perfusion. Drug Metab Dispos 1997;25:610-6. 
8 Minematsu T, Sugiyama E, Kusama M, et al. Effect of hematocrit on pharmacokinetics of tacrolimus in adult living donor liver transplant recipients. Transplant Proc 2004;36:1506-11.

9 Zahir $\mathrm{H}, \mathrm{McC}$ aughan $\mathrm{G}$, Gleeson $\mathrm{M}$, et al. Factors affecting variability in distribution of tacrolimus in liver transplant recipients. Br J Clin Pharmacol 2004;57:298-309.

10 Størset E, Holford N, Midtvedt K, et al. Importance of hematocrit for a tacrolimus target concentration strategy. Eur J Clin Pharmacol 2014;70:65-77.

11 Limsrichamrern S, Chanapul C, Mahawithitwong P, et al. Correlation of hematocrit and tacrolimus level in liver transplant recipients. Transplant Proc 2016;48:1176-8.

12 Zeevi A, Duquesnoy R, Eiras G, et al. Immunosuppressive effect of FK-506 on in vitro lymphocyte alloactivation: synergism with cyclosporine A. Transplant Proc 1987:19:40-4.

13 Kyles AE, Gregory CR, Craigmill AL. Comparison of the in vitro antiproliferative effects of five immunosuppressive drugs on lymphocytes in whole blood from cats. Am J Vet Res 2000:61:906-9.

14 Plosker GL, Foster RH. Tacrolimus: a further update of its pharmacology and therapeutic use in the management of organ transplantation. Drugs 2000;59:323-89.

15 Schultz LW, Martin PK, Liang J, et al. Atomic Structure of the Immunophilin FKBP13FK506 Complex: insights into the Composite Binding Surface for Calcineurin. J Am Chem Soc 1994;116:3129-30.
16 Nigam SK, Jin YJ, Jin MJ, et al. Localization of the FK506-binding protein, FKBP 13, to the lumen of the endoplasmic reticulum. Biochem J 1993;294:511-5.

17 Walensky LD, Gascard P, Fields ME, et al. The 13-kD FK506 binding protein, FKBP13, interacts with a novel homologue of the erythrocyte membrane cytoskeletal protein 4.1. J Cell Biol 1998;141:143-53.

18 Venkataramanan R, Jain A, Warty VS, et al. Pharmacokinetics of FK 506 in transplant patients. Transplant Proc 1991;23:2736-40.

19 Zheng S, Easterling TR, Umans JG, et al. Pharmacokinetics of tacrolimus during pregnancy. Ther Drug Monit 2012;34:660-70.

20 Spallanzani V, Bindi L, Bianco I, et al. Red blood cell exchange as an approach for treating a case of severe tacrolimus overexposure. Transfus Apher $\mathrm{SCl}$ 2017; 56:238-40.

21 Holtick U, Albrecht M, Chemnitz JM, et al. Bone marrow versus peripheral blood allogeneic haematopoietic stem cell transplantation for haematological malignancies in adults. Cochrane Database Syst Rev 2014;4:CD010189.

22 Uchino M, Ogawa Y, Uchino Y, et al. Comparison of stem cell sources in the severity of dry eye after allogeneic haematopoietic stem cell transplantation. $\mathrm{Br} J$ Ophthalmol 2012;96:34-7 